\title{
Cyclin A1 protein shows haplo-insufficiency for normal fertility in male mice
}

\author{
Tiffany van der Meer, W-Y Iris Chan ${ }^{1}$, Luis S Palazon, Conrad Nieduszynski ${ }^{1}$, Martin Murphy ${ }^{2}$, \\ Joelle Sobczak-Thépot ${ }^{2}$, Mark Carrington ${ }^{1}$ and William H Colledge
}

Department of Physiology, University of Cambridge, Cambridge CB2 3EG, UK, ${ }^{1}$ Department of Biochemistry, University of Cambridge, Cambridge CB2 1GA, UK and ${ }^{2}$ INSERM U370, Faculté Necker, 156 Rue de Vaugirard, 75015 Paris, France

Correspondence should be addressed to W H Colledge; Email: whc23@cam.ac.uk

$T$ van der Meer is currently at The Netherlands Cancer Institute, Plesmanlaan 121, 1066 CX Amsterdam, The Netherlands and J Sobczak-Thépot is currently at Université Pierre et Marie Curie, CNRS UMR7098, case 265, 4 Place Jussieu, 75005 Paris, France

\begin{abstract}
In higher eukaryotes, the cyclins constitute a family of proteins involved in progression through the cell cycle. The cyclin A1 gene (Ccna1) is expressed during meiosis and is required for spermatogenesis. Targeted disruption of the Ccna1 gene with a LacZ reporter gene has allowed us to study the expression pattern of this gene in more detail. We have confirmed expression in mouse pre-meiotic spermatocytes and also detected expression in the accessory olfactory bulb, hippocampus and amygdala of the adult brain. We have also found that the amount of cyclin A1 protein influences the fertility of male mice and its action is modulated by genetic background. On an outbred genetic background (129S6/SvEv $\times$ MF1), Ccna ${ }^{\text {tm1Col }}-/-$ animals are sterile due to spermatogenic arrest prior to the first meiotic division while Ccna ${ }^{\text {tm1Col }}+/-$ mice show reduced sperm production and fertility. This is even more pronounced on an inbred genetic background (129S6/SvEv) where Ccna ${ }^{\text {tm1 }}$ Col $+/-$ male mice are sterile due to a severe reduction in the total number of sperm.

Reproduction (2004) 127 503-511
\end{abstract}

\section{Introduction}

The cyclins form a large protein family involved in the regulation of the eukaryotic cell cycle. Cyclin binding is a key event required for activation of cyclin-dependent protein kinases (CDKs), which regulate progression between phases of the cell cycle. There are four types of cyclins: A, B, D and E. D- and E-type cyclins are involved in the passage through G1 and entry into the S-phase. B-type cyclins are necessary for mitosis or meiosis. Evidence from the point of cell cycle arrest in ablation experiments indicate that A-type cyclins act at two points in the cell cycle, at the beginning of the Sphase and during mitosis. Two A-type cyclins (A1 and A2) have been identified in Xenopus (Howe et al. 1995), mice (Sweeney et al. 1996, Ravnik \& Wolgemuth 1999) and humans (Henglein et al. 1994, Yang et al. 1997).

Cyclin A1 differs from the other cyclins in that its expression pattern is predominantly restricted to the germ line. Its precise pattern of expression has been investigated in male mice and compared with that of cyclin A2. While cyclin A2 is exclusively expressed during mitotic proliferation prior to the meiotic cycle and during the pre-meiotic S-phase, cyclin A1 expression is restricted to meiotic cells. Specifically, cyclin A1 mRNA and protein are first detected in late pachytene spermatocytes with the amount of protein rising to a maximum during diplotene (Ravnik \& Wolgemuth 1999). As with the role of cyclin A2/CDK during mitosis, the role of cyclin A1/CDK during meiosis remains obscure. However, cyclin A1 is essential for the completion of male meiosis as mice homozygous for a null mutation of cyclin A1 are sterile due to the complete arrest of spermatogenesis in the latter stages of meiotic prophase, while females appear to be phenotypically normal and fertile (Liu et al. 1998). It has been proposed that the role of cyclin A1/CDK may include the phosphorylation of $\mathrm{Cdc} 25$ phosphatases which are required for the activation of the cyclin B/CDK1 complex (or M-phase promoting factor) essential for the G2/M transition (Liu et al. 2000).

In humans, there are data that suggest a role for cyclin A1 in haematopoiesis and more definitely in the development of myeloid leukaemia. Very low levels of cyclin A1 are detected in normal haematopoietic tissues, and relatively high levels have been detected in several leukaemic cell lines and in the peripheral blood cells of 
patients with certain haematological malignancies (Kramer et al. 1998). Transgenic mice over-expressing cyclin A1 in the myeloid lineage exhibit abnormal myelopoiesis and can develop acute myeloid leukaemia (Liao et al. 2001). Although the role of cyclin A1 in the development of acute myeloid leukaemia is unknown, there is some evidence to suggest that the kinase activity of cyclin A1/CDK2 may enhance the activity of the B-MYB transcription factor which is essential for the G1/S transition in leukaemic cells (Muller-Tidow et al. 2001). Human cyclin A1/CDK2 can phosphorylate other important cell cycle regulators such as E2F- and Rb- related proteins (Yang et al. 1999).

We have described here the generation of transgenic mice in (designated Ccna $1^{\mathrm{tm} 1 \mathrm{Col}}$ ) which the cyclin A1 gene (Ccna1) has been disrupted and tagged with a LacZ reporter gene. We have confirmed previous reports that homozygous mutant males are sterile due to a failure to complete spermatogenesis (Liu et al. 1998). We have also made the new observation that $\mathrm{Ccna}^{\mathrm{tm} 1 \mathrm{Col}}+/-$ male mice show reduced fertility because of a reduction in sperm numbers and that the severity of this phenotype is strain dependent. These data suggested that cyclin A1 is acting as a dose-dependent regulator of the successful production of haploid cells and its activity is modulated by genetic background. If applicable to humans, cyclin A1 levels and/or activity may contribute to idiopathic cases of oligospermia (reduced sperm numbers) in infertile men.

\section{Materials and Methods \\ Generation of Ccna $1^{\text {tm1 Col }}$ mice}

CCB ES cells (129S6Sv/Ev) were grown on primary embryonic fibroblast feeder cells in Dulbecco's modified Eagle's medium/F12 (Gibco, Invitrogen Life Technologies, Paisley, Scotland) supplemented with $20 \%$ fetal calf serum (LabTech International, Lewes, East Sussex, UK), $1 \mathrm{mM}$ L-glutamine (Sigma, Poole, Dorset, UK), $10^{-4} \mathrm{M} \beta$-mercaptoethanol (Sigma) and 100 units/ml each of penicillin and streptomycin (Sigma). ES cells $\left(2 \times 10^{7}\right)$ were electroporated with $0.5 \mu \mathrm{g}$ of the linearised targeting vector at $250 \mathrm{~V}$ and $960 \mu \mathrm{F}$ capacitance. ES cell clones were selected in $250 \mu \mathrm{g} / \mathrm{ml} \mathrm{G} 418$ (Sigma) and screened by Southern analysis for targeting events. Two independently targeted ES cell clones were used to generate chimaeric mice by injection into $\mathrm{C} 57 \mathrm{BL} / 6$ blastocysts. Animal experiments were performed in accordance with UK legal requirements. Male chimaeras were bred with MF1 (outbred strain) or 129S6/SvEv (inbred strain) females and heterozygous offspring identified by Southern analysis and/or PCR. Primers B158 (tgctcaagtcagatctccacttcc) and B159 (ttatattcttccccaacctccacc) were used to amplify a $1 \mathrm{~kb}$ fragment from the intact Ccna1 gene. Primers (gaagaactcgtcaaggcgatagaa and gggtggagagcgtattcggctat) were used to amplify a 765 bp fragment from the neomycin phosphotransferase (neo) gene as a marker for the targeted allele. Reaction conditions were $95^{\circ} \mathrm{C}$ for $5 \mathrm{~min}$ followed by 40 cycles of $93{ }^{\circ} \mathrm{C}$ for $30 \mathrm{~s}, 60^{\circ} \mathrm{C}$ for $1 \mathrm{~min}$ and $70{ }^{\circ} \mathrm{C}$ for $1 \mathrm{~min}$. A null mutation at the Ccna1 locus was confirmed by both RTPCR and western analysis. The RT-PCR analysis was performed using primers RTF (atgcatcgccagagctccaagagtggagtc) and RTR (cctctgcatactccgttacgttaatcacat) which span intron II of the Ccna1 gene and amplify a $0.5 \mathrm{~kb}$ fragment. The reaction conditions were first-strand cDNA synthesis: $50{ }^{\circ} \mathrm{C}$ for $30 \mathrm{~min}, 94^{\circ} \mathrm{C}$ for $2 \mathrm{~min}$; second-strand cDNA synthesis and PCR amplification: 10 cycles of $94^{\circ} \mathrm{C}$ for $20 \mathrm{~s}$, $65^{\circ} \mathrm{C}$ for $30 \mathrm{~s}$ and $68^{\circ} \mathrm{C}$ for $30 \mathrm{~s}$ followed by 25 cycles of $94^{\circ} \mathrm{C}$ for $20 \mathrm{~s}, 65^{\circ} \mathrm{C}$ for $30 \mathrm{~s}$ and $68^{\circ} \mathrm{C}$ for $30 \mathrm{~s}$ with an extension of $5 \mathrm{~s}$ per cycle and a final cycle of $68^{\circ} \mathrm{C}$ for $7 \mathrm{~min}$. Western analysis used homogenates prepared from decapsulated testes and an anti-cyclin A1 antibody (Sweeney et al. 1996) or an anti-cyclin B2 antibody (Brandeis et al. 1998) or an anti-CDK2 antibody (sc162 from Santa Cruz Biotechnology, Sant Cruz, CA, USA).

\section{Histological analysis}

Intact tissues were fixed in 4\% paraformaldehyde in phosphate-buffered saline (PBS) and assessed for $\beta$-galactosidase expression by overnight incubation in staining solution (0.1M PBS, $2 \mathrm{mMMgCl}_{2}, 5 \mathrm{mM}$ potassium ferricyanide, $5 \mathrm{mM}$ potassium ferrocyanide and X-Gal at $1 \mathrm{mg} / \mathrm{ml}$ ). After staining, tissues were post-fixed in 4\% paraformaldehyde, embedded in paraffin wax and sectioned. The brain was fixed in $4 \%$ paraformaldehyde for $15 \mathrm{~min}$ and then set in $3 \%$ agarose and slices were cut at $2 \mathrm{~mm}$ intervals. The slices were fixed in $4 \%$ paraformaldehyde for a further $15 \mathrm{~min}$ and then washed, stained and fixed as before. Tissues were embedded in paraffin wax and $7 \mu \mathrm{m}$ sections cut and stained with haematoxylin and eosin. For staging the seminiferous cycle, Bouin-fixed, historesin-embedded adult testes were sectioned at $5 \mu \mathrm{m}$ and counter-stained with methylene blue. Spermatogenic stages were defined by morphological appearance as described by Russell et al. (1990). For cell counts, a complete cross-section (as opposed to a longitudinal section) of a stage VII tubule was selected and photographed. When necessary, several photographs were taken to cover the whole tubule. All pachytene and haploid cells on the photographs were counted. The sections were cut at $5 \mu \mathrm{m}$ and stained with methylene blue to allow good visualisation of nuclei. Only cells with complete nuclear membranes on the photographs were counted. The cells of interest were counted by the appearance of the corresponding nuclei. Since the diameter of pachytene cells and step 7 spermatids are approximately $12 \mu \mathrm{m}$ and $5 \mu \mathrm{m}$ respectively sections as thin as $5 \mu \mathrm{m}$ rarely result in overlapping of cells, which might lead to a misrepresentation in cell counting.

\section{Analysis of reproductive capability}

Eight- to nine-week-old male mice were housed in individual cages and set up with 6- to 8-week-old MF1 
females. Females were checked for the presence of a copulatory plug every morning. Any plugged female was removed and replaced. Plugged females were killed at 10 days post coitum (dpc) and examined for the number of embryos. For each male being tested, at least one littermate with a different genotype was also tested. This regime was carried out for 5 weeks. For sperm counts, the vas deferens was dissected from one side and its length measured. A $1 \mathrm{ml}$ syringe fitted with a 34 gauge blunt ended needle was used to flush $0.5 \mathrm{ml}$ of water through the vas deferens into a $1.5 \mathrm{ml}$ Eppendorf tube. After a brief vortex, $10 \mu$ l of the suspension was loaded onto a haemocytometer and the sperm were counted. The frequencies of mating and pregnancy in the male fertility test were analysed using the chi-square test of significance. A two-tailed Mann-Whitney test (Instat GraphPad Software, San Diego, CA, USA) was used to compare the results obtained in the analysis of testes weight and sperm recovery.

\section{Results}

\section{Male chimaeras showed an unusually low rate of germ-line transmission of the ES cell genome}

A standard gene-targeting strategy was used to disrupt the Ccna1 gene (Fig. 1A). The targeting vector contained a $L a c Z$ gene fused immediately after the initiator methionine of the cyclin A1 protein. The Lac $Z$ gene was expressed from the endogenous cyclin A1 promoter, which provides a convenient method of visualising Ccna1 gene expression. The targeted allele had all the protein coding exons of the Ccna1 gene deleted. Germ-line transmission of the Ccna1 null mutation was achieved from only two out of 34 male chimaeras generated from two independently targeted ES clones. This frequency of transmission (6\%) was much lower than usually observed in our laboratory where $76 \%$ of male chimaeras normally transmit the ES cell genome ( $n=58$ chimaeras). In addition, neither of the two germ-line chimaeras showed complete ES cell colonisation of the germ line as judged by transmission of agouti coat colour to offspring. Of the 34 chimaeras, 12 $(35 \%)$ failed to sire any offspring compared with a failure rate of around $7 \%(n=58$ chimaeras $)$ for other gene-targeting experiments. The Ccna1 null mutation was established on an outbred (129S6/SvEv $\times$ MF1) and an inbred (129S6/SvEv) genetic background by breeding from the two germ-line chimaeras. Offspring from outbred Ccna1 heterozygote crosses gave the expected Mendelian ratio of genotypes and viable homozygous mutant animals (Fig. 1B). The null mutation was confirmed by both RT-PCR and Western blot analysis with no mRNA or protein detected in homozygous mutant animals (Fig. 1C and D). The western blot indicated that approximately half the amount of protein was present in the testes of heterozygous mice (Fig. 1D).

\section{Ccna1 ${ }^{\text {tm1Col }}$ homozygous mutant males have small testes and are azoospermic}

The combined weight of both testes from Ccna $1^{\mathrm{tm} 1 \mathrm{Col}}$ $-1-$ mice was around $50 \%$ of the weight from age-matched Ccna $1^{\text {tm1 } \mathrm{Col}}+/+$ animals. On the outbred genetic background $(\mathrm{MF} 1 \times 129 \mathrm{~S} 6 / \mathrm{SvEv})$, pairs of testes from Ccna ${ }^{\text {tm1Col }}+/+$ mice had a weight of $0.23 \pm 0.02 \mathrm{~g}$ ( $n=5$ animals), Ccna $1^{\mathrm{tm} 1 \mathrm{Col}}+/-$ mice had a paired testes weight of $0.20 \pm 0.01 \mathrm{~g} \quad(n=9$ animals $)$ and C Cna $1^{\text {tmiCol }}-1-$ mutants had a paired testes weight of $0.12 \pm 0.002 \mathrm{~g}$ ( $n=6$ animals). There was no significant difference in the body weights of male mice at 20 weeks of age $\left(35 \pm 1.2 \mathrm{~g}\left(n=5\right.\right.$ animals) for $C_{c n a} 1^{t m 1 C o l}+/+$ mice and $36 \pm 0.98 \mathrm{~g}(n=6$ animals $)$ for $C \mathrm{cna} 1^{\mathrm{tm} 1 \mathrm{Col}}-/-$ mice).

Post-meiotic cell types (spermatids and spermatozoa) were absent from Ccna $1^{\mathrm{tm} 1 \mathrm{Col}}-1-$ testes but the spermatogonial population appeared normal (Fig. 2A and C compared with Fig. 2B and D). Degenerating cells with condensed and fragmented nuclear material identified by intense haematoxylin staining were found in the adluminal compartment of seminiferous tubules. Occasionally, large multi-nucleated cells were also present (Fig. 2D); these are often observed when spermatogenesis is disrupted (Knudson et al. 1995, Nantel et al. 1996). All cell types from the spermatogenic lineage were present in testes from Ccna $1^{\mathrm{tm} 1 \mathrm{Col}}+/-$ mice. Testes from Ccna ${ }^{\text {tm1Col }}-/-$ mice stained for $\beta$-galactosidase activity predominantly in degenerating spermatocytes (Fig. 2F). In testes from Ccnal ${ }^{\text {tm1Col }}+/-$ mice, faint staining was seen in spermatocytes with stronger staining in round spermatids (Fig. 2E). Spermatozoa showed little or no staining and no staining was observed in ovaries or eggs (not shown). The testes of control wild-type mice also showed no staining.

The lumen of the vas deferens and epididymis from wildtype mice (Fig. 2G and I respectively) were packed with spermatozoa. In contrast, spermatozoa were absent from the vas deferens (Fig. 2H) and epididymis (Fig. 2J) from Ccna $1^{\mathrm{tm} 1 \mathrm{Col}}-/-$ mice. The lumen of the epididymis from Ccna $1^{\text {tm } 1 \mathrm{Col}}-/-$ mice contained many degenerating spermatocytes and some giant multi-nucleated cells.

\section{Cyclin A1 is haplo-insufficient for normal male fertility due to reduced sperm numbers}

Only one out of five Ccna $1^{\mathrm{tm} 1 \mathrm{Col}}+/-$ breeding pairs on the outbred genetic background (MF1 × 129S6/SvEv) produced offspring and no pups were ever obtained from heterozygous matings on the inbred genetic background (129S6/SvEv). Preliminary breeding experiments showed that $C_{\mathrm{cna}} 1^{\mathrm{tm} 1 \mathrm{Col}}+/-$ females were fertile so the fertility of males was assessed in more detail. No differences were observed in the ability of male mice of any genotype to plug Ccna ${ }^{\text {tm1Col }}+1+$ females (Fig. 3A). However, there was a significant difference in the pregnancy rate between each genotype. Around $90 \%$ of females that were plugged 
$\mathbf{A}$

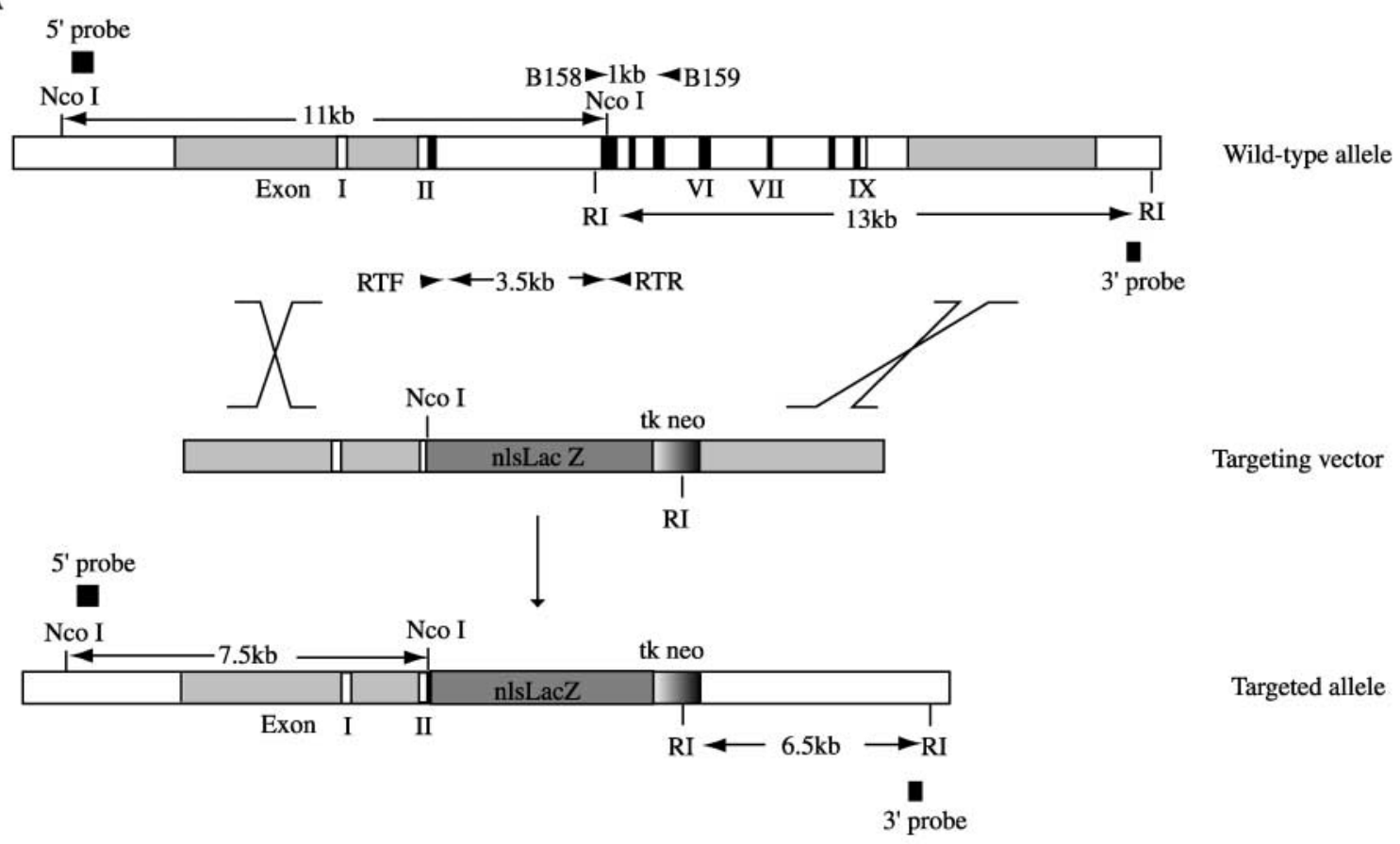

s

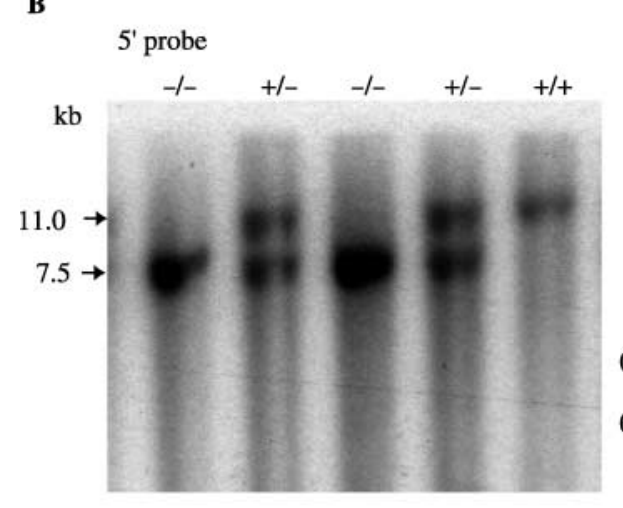

C

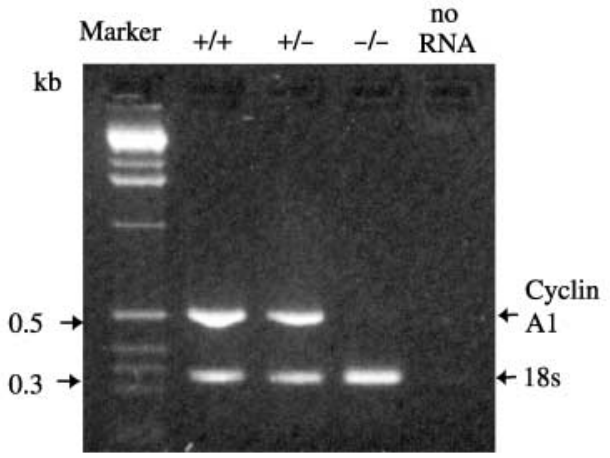

D

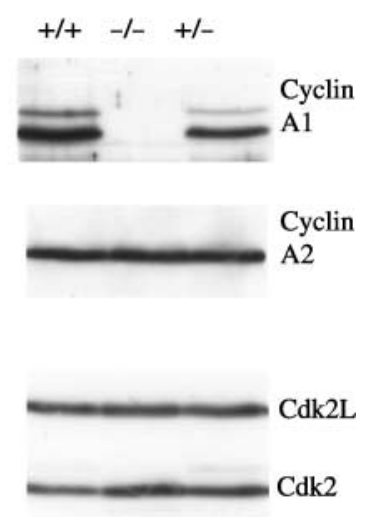

Figure 1 Generation of $C \mathrm{cna} 1^{\mathrm{tm} 1 \mathrm{Col}}$ mice. (A) Targeted disruption of the murine cyclin A1 gene (Ccna1): the targeting vector contains $5 \mathrm{~kb}$ of $5^{\prime}$ homology including the Ccna 1 promoter and $3.5 \mathrm{~kb}$ of $3^{\prime}$ homology (homology shown in light grey). The LacZ reporter gene (dark grey) encodes a $\beta$-galactosidase tagged with a nuclear localisation signal sequence $(\mathrm{nls})$ and is driven by the Ccna1 promoter. The neo selection cassette is under the control of the thymidine kinase (tk) promoter (gradation to black). Homologous recombination results in loss of all coding exons II to IX (coding region shown in black). RI, EcoRI restriction site. B158, B159, RTF, RTR indicate primer locations. (B) Southern analysis of Ccna ${ }^{\text {tm1Col }}$ mice generated from heterozygote intercrosses: genomic DNA was digested with Ncol and hybridised with a $5^{\prime}$ probe external to

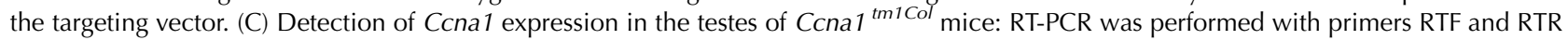
spanning intron II of the Ccna1 gene to amplify a product of $0.5 \mathrm{~kb}$ from cyclin A1 cDNA. As a positive control an 18S rRNA primer pair which amplifies a $0.3 \mathrm{~kb}$ product was used. (D) Western blot analysis of testes lysates: anti-cyclin A1 antibodies detected two cyclin A1 polypeptides with relative molecular masses of $54 \mathrm{kDa}$ and $57 \mathrm{kDa}$ in the testes of both $C \mathrm{Cna} 1^{\mathrm{tm} 1 \mathrm{Col}}+/+$ and $+/-$, but not $-/-$ mice. The signal from the

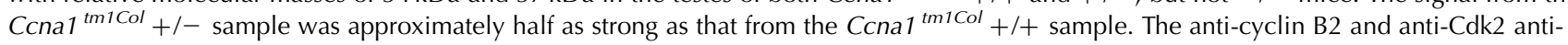
bodies acted as positive controls for loading differences.

by wild-type males became pregnant irrespective of whether the males were outbred or inbred (Fig. 3B). The conception rate was reduced to $16 \%$ for heterozygous males of outbred genetic background while inbred heterozygous males gave no pregnancies from 24 copulatory plugs (Fig. 3B). Thus, Ccnat ${ }^{\mathrm{tm} 1 \mathrm{Col}}-/-$ mice could not be obtained on an inbred genetic background because of the infertility of the $C \mathrm{Cna} 1^{\mathrm{tm} 1 \mathrm{Col}}+/-$ males on this genetic background. As expected from the absence of sperm, outbred $\mathrm{C} \mathrm{Cna} 1^{\mathrm{tm} 1 \mathrm{Col}}-/-$ males also failed to conceive.

To establish the reason for the reduced fertility of C Cna $1^{{ }^{\mathrm{tm}} 1 \mathrm{Col}}+/-$ mice, the number of sperm recovered 


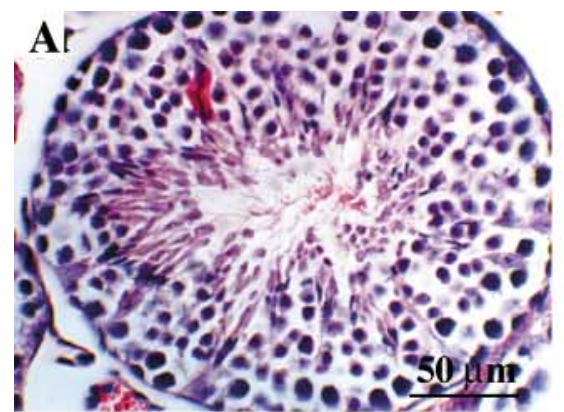

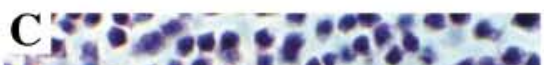

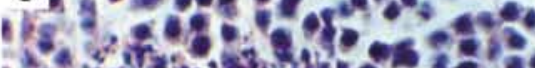

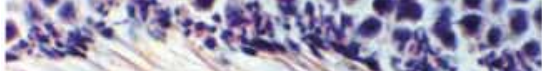

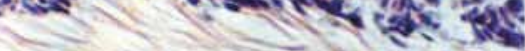
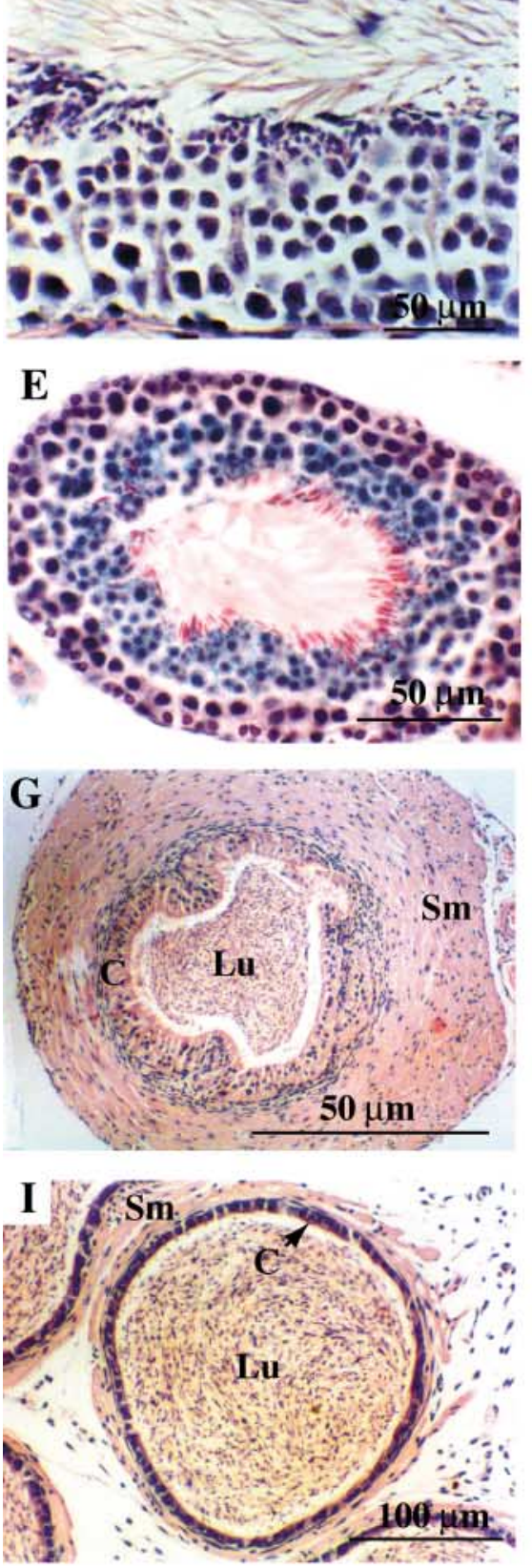
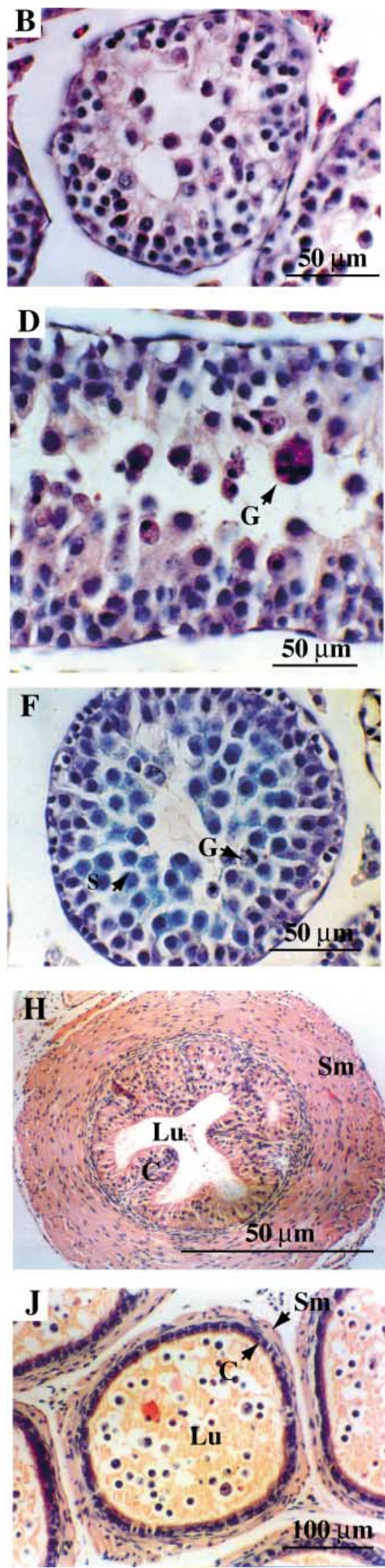

Figure 2 Histology of the male reproductive system. Seminiferous tubules from

Ccna $1^{{ }^{t m 1 C o l}}$ - / - mice (B, D and F) lack postmeiotic cell types and are characterised by degenerating cells with condensed and fragmented nuclear material and giant multinucleated cells $(\mathrm{G})$. The spermatogenic lineage is intact in seminiferous tubules from

CCna $1^{\text {tm } 1 \mathrm{Col}}+/+$ and $+/-$ mice $(\mathrm{A}, \mathrm{C}$ and $\mathrm{E})$. For $C \mathrm{Cna} 1^{\text {tm1 } 1 \mathrm{Col}}$ testes stained for $\beta$-galactosidase activity (E and F), a small amount of staining was seen in some spermatocytes with much stronger staining in round spermatids in $+/-$ testes (E) while the blue stain was predominantly seen in spermatocytes $(S)$ in $-1-$ testis $(\mathrm{F})$. The lumen $(\mathrm{Lu})$ of the vas deferens $(\mathrm{G})$ and epididymis (I) from $\mathrm{CCna} 1^{\mathrm{tm} 1 \mathrm{Col}}$ $+/+$ mice contained spermatozoa, which were absent from the vas deferens $(\mathrm{H})$ and epididymis (J) of Ccna $1^{\text {tm1 Col }}-/$ - mice. Sm, smooth muscle; C, cuboidal epithelia. All sections were cut at $7 \mu \mathrm{m}$ and stained with haematoxylin and eosin. 
$\mathbf{A}$

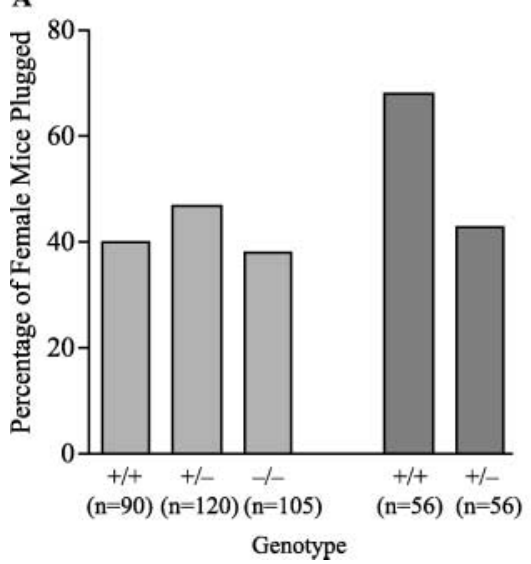

B

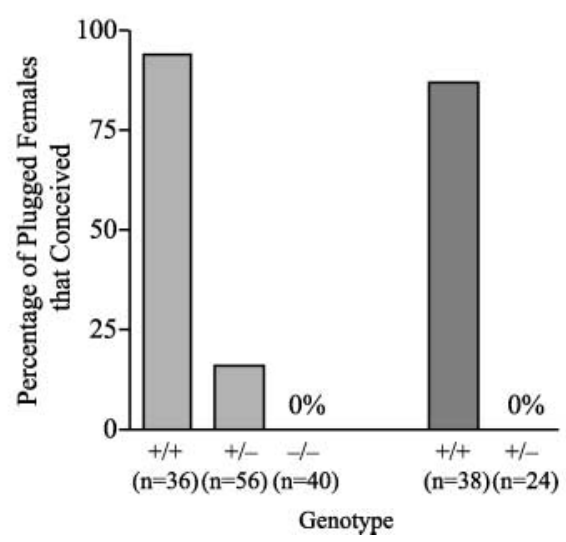

C

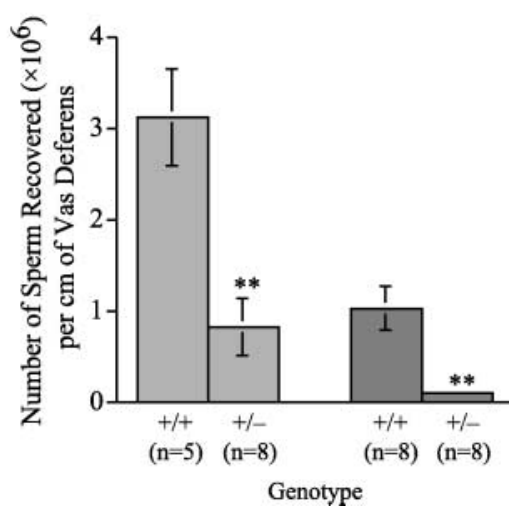

Figure 3 Fertility analysis of $C c n a 1^{t m 1 C o l}$ mice. (A) Frequency of copulatory plug. Seven males of each genotype were housed with females over a 4-week period and copulatory plugs recorded. The total number of females to which each male had access is given in parentheses.

(B) Frequency of conception. The number of females with a copulatory plug (in parentheses) that became pregnant was recorded. (C) Recovery of sperm from the vas deferens. Sperm were flushed from the vas deferens of $C c n a 1^{t m 1 C o l}+/+$ and $+/-$ males. No sperm were recovered from homozygous $-/-$ outbred animals. The number of males analysed is shown in parentheses. **P<0.001 (two-tailed Mann-Whitney). For all three panels, outbred mice are shown in light grey, inbred mice in dark grey.

from the vas deferens was measured (Fig. 3C). On both the outbred and inbred genetic backgrounds, significantly less sperm were recovered from $\mathrm{Ccna}^{\mathrm{tm} 1 \mathrm{Col}}+/-$ mice than from Ccna $1^{\text {tm1Col }}+/+$ mice $(P<0.001$, two-tailed Mann-Whitney). Significantly fewer $(P=0.03$, two-tailed Mann-Whitney) sperm were also recovered from inbred (129S6/SvEv) Ccna ${ }^{\text {tm1Col }}+/+$ males compared with the outbred Ccna1 ${ }^{\text {tm1Col }}+/+$ males, consistent with the reduced fecundity of inbred strains of mice in general (Fig. 3C). No sperm were isolated from any Ccna $1^{\text {tm1Col }}-1-$ mice $(n=6)$.

To determine the origin of the reduced sperm numbers in the Ccna $1^{\text {tm1Col }}+/-$ mice, pachytene spermatocytes and haploid spermatids were quantitated in testes sections from mice on the outbred and inbred genetic backgrounds (Fig. 4). No significant differences were found in the number of pachytene cells between $\mathrm{Ccna}^{\mathrm{tm} 1 \mathrm{Col}}+/-$ and C cna $1^{\text {tmicol }}+/+$ mice of the same genetic background. In contrast, the number of haploid spermatids was significantly lower in Ccna $1^{\text {tmicol }}+/-$ than in Ccna $1^{\text {tmicol }}$ $+/+$, indicating a greater failure of some cells to complete meiosis (Table 1). More cells failed to complete meiosis on the inbred background (Table 1).

\section{Cyclin A1 is also expressed in the brain}

To determine whether the cyclin A1 gene is transcribed exclusively in the testes, other tissues were examined for $\beta$-galactosidase activity. Staining was observed in brain slices from both Ccna $1^{\mathrm{tm} 1 \mathrm{Col}}+/-$ and $-/-$ but not in $+/+$ controls (Fig. 5A). Similar staining patterns were observed in mice derived from both targeted ES clones and no obvious difference in the size of these staining regions was apparent between $+/-$ and $-1-$ animals. Intense staining was found in the accessory olfactory bulb, the dentate gyrus, the Ammon's horn of the hippocampus and in the amygdala. Less intense staining was seen in the thalamus, hypothalamus and some cell layers of the cerebellum (not shown). $\beta$-Galactosidase activity was not observed in any other tissues examined (lung, heart, spleen, liver, kidney and ovaries) or in post-implantation embryos at $10.5 \mathrm{dpc}(n=13)$ and $12.5 \mathrm{dpc}(n=12)$ (data not shown). To confirm that the Lac $Z$ expression pattern reflected Ccna1 expression, the expression of endogenous cyclin A1 in the brain was examined by RT-PCR. Cyclin A1 mRNA was detected in the brain of C Cna $1^{\mathrm{tm}^{1 \mathrm{Col}}+/+}$ and Ccnat ${ }^{\text {tm1Col }}+/-$ mice but not in the brain of Ccna $1^{\text {tm1Col }}-1-$ mutant animals (Fig. 5B).

\section{Discussion}

The disruption of spermatogenesis in Ccna $1^{\text {tm1Col }}-1-$ mice was consistent with that reported by Liu et al. (1998) and confirms that cyclin A1 is essential for meiosis in male germ cells. Liu et al. (1998), however, did not describe a phenotype in heterozygous mice. The data presented here show that Ccna ${ }^{\text {tmicol }}+/-$ males with an outbred genetic background (MF1 × 129S6/SvEv) are subfertile and those with an inbred genetic background (129S6/SvEv) are sterile. On both these genetic backgrounds, significantly fewer sperm were recovered from the reproductive tract of $\mathrm{CCna}^{\mathrm{tm} 1 \mathrm{Col}}+/-$ animals compared with Ccna $1^{\mathrm{tm} 1 \mathrm{Col}}+/+$, suggesting that a low sperm count is responsible for this sub-fertility. It has long been recognised that reduced sperm numbers (oligozoospermia) can severely compromise normal fertility in humans.

Western analysis showed that $C$ cna $1^{\text {tm1Col }}+/-$ mice have around half the cyclin A1 protein compared with normal mice. Cyclin A1 haplo-insufficiency reduces the number of cells that make the meiotic transition from 


\section{$+/+$ stage IV}
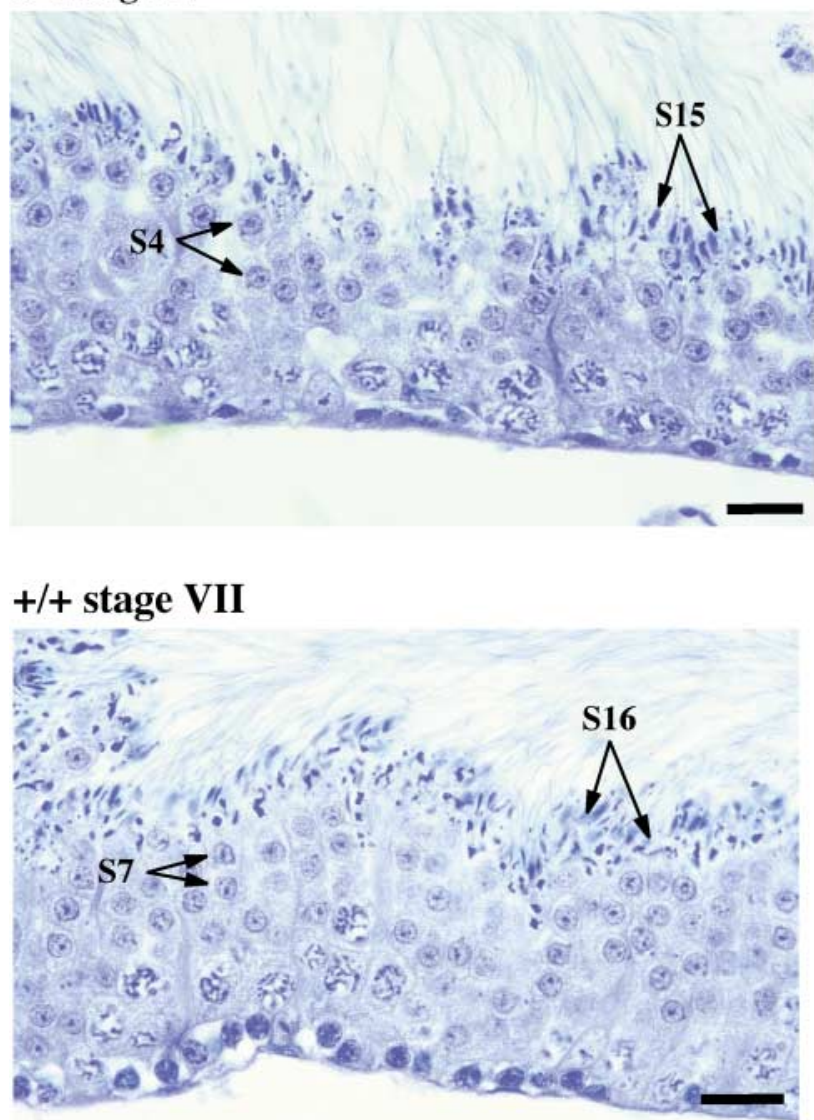

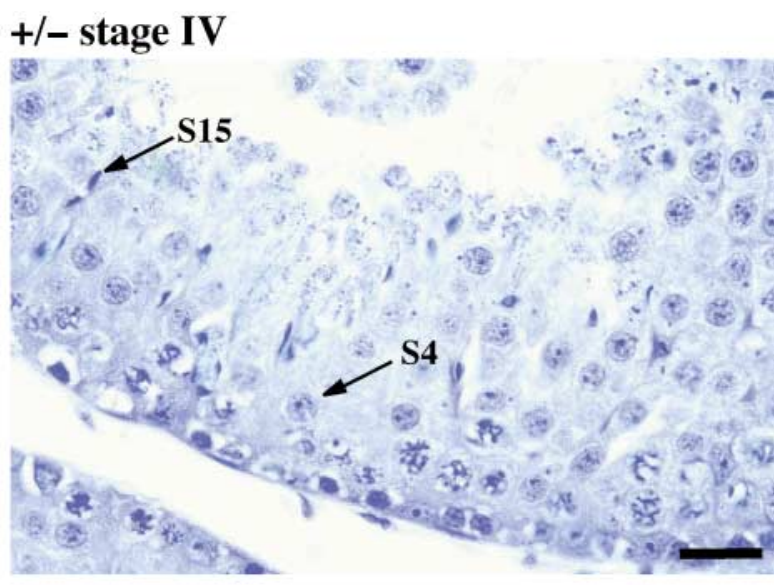

\section{+/- stage VII}

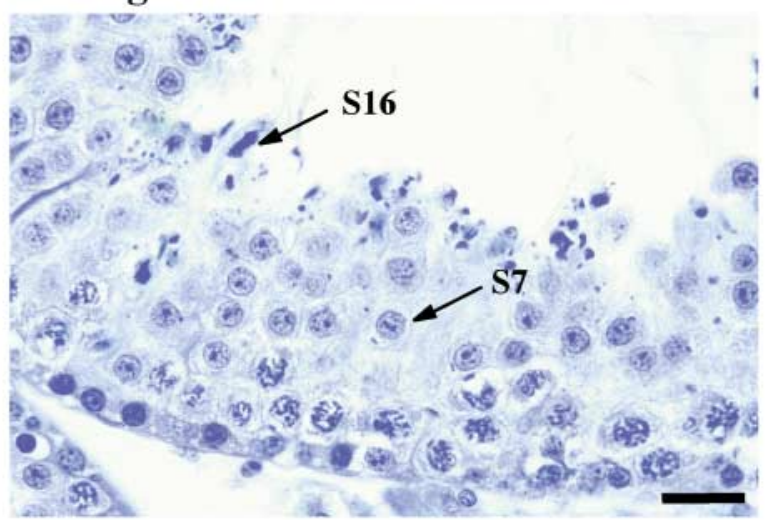

Figure 4 Histological evaluation of meiosis in heterozygous mouse testes. Comparison of seminiferous tubules from Ccna ${ }^{\mathrm{tm} 1 \mathrm{Col}}+/+$ mice (lefthand panels) and +/- mice (right-hand panels) on an inbred genetic background (129S6/SvEv). At both the morphological stages shown (stages IV and VII of spermatogenesis) the number of haploid spermatids and of spermatozoa (with tails in the lumen) was significantly reduced in heterozygotes. Roman numerals correspond to particular stages of the spermatogenic cycle as defined by Russell et al. (1990). S4/7/15/16, step 4/7/12/15/16 spermatids. Scale bars represent $20 \mu \mathrm{m}$.

spermatocyte to haploid spermatid (Table 1). This may be caused by an altered transit time through meiosis and increased loss of spermatocytes. It is unlikely to be caused by selective loss of spermatids carrying the mutated Ccna $1^{\mathrm{tm} 1 \mathrm{Col}}$ allele since functional sperm with this allele are produced by outbred Ccna1 ${ }^{\text {tm1Col }}+/-$ mice and the availability of cyclin A1 protein to each spermatocyte will be similar via protein movement between cytoplasmic bridges (Braun et al. 1989). Interestingly, haplo-insufficiency has also been found for the mitotic checkpoint protein MAD2, suggesting that the cell cycle may be particularly sensitive to changes in the amount of regulatory proteins (Michel et al. 2001).

As heterozygous inbred males are sterile, it is perhaps surprising that male chimaeras (generated from 129S6/ SvEv ES cells) transmitted the targeted allele. It is noteworthy that the rate of germ-line transmission was considerably lower than for other gene-targeted mice that we

Table 1 Comparison of pachytene and haploid cell numbers in $C \mathrm{Cna} 1^{\mathrm{tm} 1 \mathrm{Col}}+/+$ and $+/-$ mice. Cells were counted in cross sections of seminiferous tubules. Values are given as mean \pm S.E.M. per tubule cross section, with number of tubules examined in parentheses. Analyses were performed using testes from four outbred and two inbred mice of each genotype.

\begin{tabular}{lccc}
\hline Genotype & Strain & No. of pachytene cells/tubule cross section & No. of haploid cells/tubule cross section \\
\hline$+/+$ & Outbred (129S6/SvEv $\times$ MF1) & $64 \pm 3.7(16)$ & $153 \pm 10.4(16)$ \\
$+/-$ & & $65 \pm 3.9(16)$ & $122 \pm 7.8(16) *$ \\
$+/+$ & Inbred (129S6/SvEv) & $84 \pm 8.1(8)$ & $207 \pm 26.9(8)$ \\
$+/-$ & & $74 \pm 6.8(8)$ & $85 \pm 3.9(8) * *$ \\
\hline
\end{tabular}

${ }^{*} P=0.024,{ }^{* *} P=0.0005$, statistically significant differences between $C \mathrm{Cna} 1{ }^{\mathrm{tm} 1 \mathrm{Col}}+/ \mathrm{+}$ and $+/-$ mice are indicated (two-tailed, Student's $t$-test). 

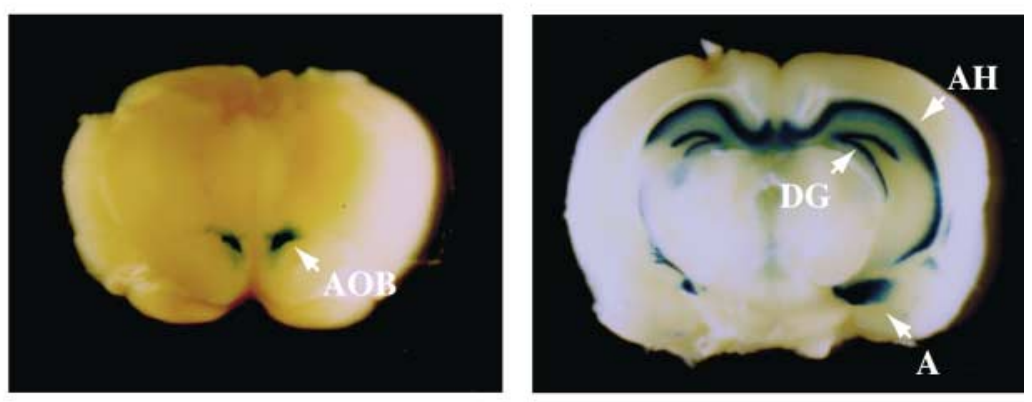

B

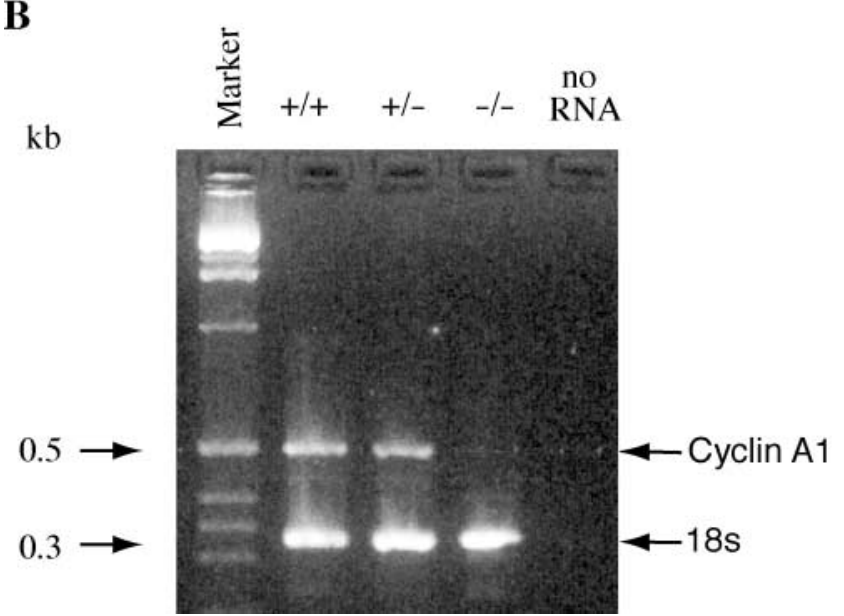

have generated and many of the male chimaeras failed to produce any offspring. Partial germ-line transmission was only obtained from two chimaeras and pups were obtained from both ES cell (12956/SvEv)-derived sperm and host blastocyst-derived sperm $(\mathrm{C} 57 \mathrm{Bl} / 6)$. It is likely that the ES cell-derived sperm required the presence of C57BI/6 sperm to achieve a total sperm count above the threshold required for fertility. Interestingly, the Ccna 1 targeted allele generated by Liu et al. (1998) was transmitted through female chimaeras.

The $\beta$-galactosidase staining pattern in the testes was consistent with the cyclin A1 promoter initiating expression of the $L a c Z$ reporter gene in the appropriate developmentally regulated manner. Expression was initiated in spermatocytes but also continued in haploid spermatids where the cyclin A1 protein is not usually found (Sweeney et al. 1996). This is probably due to the persistence of $\beta$-galactosidase mRNA and/or protein beyond the meiotic divisions consistent with our observations in transgenic mice expressing a cyclin A1-promoted LacZ transgene (J $\mathrm{S}-\mathrm{T}$, unpublished observations).

The $\beta$-galactosidase staining in the brain suggested that cyclin A1 expression is not restricted to germ cells. The presence of cyclin A1 transcripts in the brain was confirmed by RT-PCR. Expression of cyclin A1 in the brain has not been reported in the mouse but was detected at low levels in humans (Yang et al. 1997) and a number of the CCNA1 gene.

\section{Acknowledgements}

\section{References}

Figure 5 (A) Detection of cyclin A1 expression in the brain. Brain from a Ccna $1^{\text {tm1Col }}-1$ - adult male bisected through the cerebral hemispheres in the coronal plane and stained for $\beta$-galactosidase activity. AOB, accessory olfactory bulb; AH, Ammon's horn (hippocampus); DG, dentate gyrus (hippocampus);

A, amygdala. (B) Detection of cyclin A1 expression in the forebrain by RT-PCR. RT-PCR was carried out with 100 ng total RNA prepared from the forebrain of adult mice. Two specific primer pairs were used: RTF and RTR, which span intron II of the cyclin A1 gene and amplify a PCR product of $0.5 \mathrm{~kb}$ from cyclin A1 cDNA. As an internal control an $18 \mathrm{~S}$ rRNA primer/competimer mix (Ambion, Huntingdon, Cambridge, UK) was used, these primers amplify a $0.3 \mathrm{~kb}$ product from $18 \mathrm{~S}$ cDNA.

human expressed sequence tags for cyclin $\mathrm{A} 1$ have been found in the brain. The role that cyclin A1 might have in the brain is not clear as Ccnat ${ }^{\text {tmicol }}-/$ - mutants exhibited no obvious abnormal behaviour. Future tests may reveal whether an absence of cyclin A1 protein in key brain regions has any measurable effect on odourant identification, behaviour or memory.

In conclusion, we have shown that homozygous normal levels of cyclin A1 are essential for normal fertility in male mice and that the severity of haplo-insufficiency is strain dependent. Cyclin A1 has a similar pattern of expression in mice and humans and it is likely to have the same essential role during spermatogenesis in both species. It would be interesting to investigate human cases of idiopathic oligozoospermia and azoospermia for mutations in

We are very grateful to the animal house staff for dedicated animal husbandry and to Ms June Goose, Elizabeth Rice and Clare Ellis for genotyping the mouse stocks. This work was supported by an MRC studentship awarded to T vd M. W H C is supported by The Ford Physiology Fund.

Brandeis $M$, Rosewell I, Carrington $M$, Crompton $T$, Jacobs MA, Kirk J, Gannon J \& Hunt T 1998 Cyclin B2-null mice develop 
normally and are fertile whereas cyclin B1-null mice die in utero. PNAS 95 4344-4349.

Braun RE, Behringer RR, Peschon JJ, Brinster RL \& Palmiter RD 1989 Genetically haploid spermatids are phenotypically diploid. Nature $337373-376$

Henglein B, Chenivesse X, Wang J, Eick D \& Brechot C 1994 Structure and cell cycle-regulated transcription of the human cyclin A gene. PNAS 91 5490-5494.

Howe JA, Howell M, Hunt T \& Newport JW 1995 Identification of a developmental timer regulating the stability of embryonic cyclin A and a new somatic A-type cyclin at gastrulation. Genes and Development 9 1164-1176.

Knudson CM, Tung KS, Tourtellotte WG, Brown GA \& Korsmeyer S] 1995 Bax-deficient mice with lymphoid hyperplasia and male germ cell death. Science 270 96-99.

Kramer A, Hochhaus A, Saussele S, Reichert A, Willer A \& Hehlmann R 1998 Cyclin A1 is predominantly expressed in hematological malignancies with myeloid differentiation. Leukemia $\mathbf{1 2}$ 893-898.

Liao C, Wang XY, Wei HQ, Li SQ, Merghoub T, Pandolfi PP \& Wolgemuth DJ 2001 Altered myelopoiesis and the development of acute myeloid leukemia in transgenic mice overexpressing cyclin A1. PNAS 98 6853-6858.

Liu D, Matzuk MM, Sung WK, Guo Q, Wang P \& Wolgemuth DJ 1998 Cyclin A1 is required for meiosis in the male mouse. Nature Genetics 20 377-380.

Liu D, Liao C \& Wolgemuth DJ 2000 A role for cyclin A1 in the activation of MPF and G2-M transition during meiosis of male germ cells in mice. Developmental Biology 224 388-400.

Michel LS, Liberal V, Chatterjee A, Kirchwegger R, Pasche B, Gerald W, Dobles M, Sorger PK, Murty VV \& Benezra R 2001 MAD2 haplo-insufficiency causes premature anaphase and chromosome instability in mammalian cells. Nature 409 355-359.
Muller-Tidow C, Wang W, Idos GE, Diederichs S, Yang R, Readhead C, Berdel WE, Serve H, Saville M, Watson R \& Koeffler HP 2001 Cyclin A1 directly interacts with B-myb and cyclin A1/cdk2 phosphorylate B-myb at functionally important serine and threonine residues: tissue-specific regulation of B-myb function. Blood $\mathbf{9 7}$ 2091-2097.

Nantel F, Monaco L, Foulkes NS, Masquilier D, LeMeur M, Henriksen K, Dierich A, Parvinen M \& Sassone-Corsi P 1996 Spermiogenesis deficiency and germ-cell apoptosis in CREM-mutant mice. Nature 380 159-162.

Ravnik SE \& Wolgemuth DJ 1999 Regulation of meiosis during mammalian spermatogenesis: the A-type cyclins and their associated cyclin-dependent kinases are differentially expressed in the germcell lineage. Developmental Biology 207 408-418.

Russell LD, Ettlin RA, Sinha-Hakim AP \& Clegg ED 1990 Staging for laboratory species. In Histological and Histopathological Evaluation of the Testis, ch 4, pp 119-161. Clearwater, FL: Cache River Press.

Sweeney C, Murphy M, Kubelka M, Ravnik SE, Hawkins CF, Wolgemuth DJ \& Carrington M 1996 A distinct cyclin A is expressed in germ cells in the mouse. Development 122 53-64.

Yang R, Morosetti R \& Koeffler HP 1997 Characterization of a second human cyclin A that is highly expressed in testis and in several leukemic cell lines. Cancer Research 57 913-920.

Yang R, Muller C, Huynh V, Fung YK, Yee AS \& Koeffler HP 1999 Functions of cyclin A1 in the cell cycle and its interactions with transcription factor E2F-1 and the Rb family of proteins. Molecular and Cellular Biology 19 2400-2407.

Received 4 September 2003

First decision 30 December 2003

Accepted 28 January 2004 